\title{
REACTION OF N-CHLOROSULFONYLISOCYANATE WITH UNSATURATED POLYMERS. ROUTE TO A SYNTHESIS OF POLYAMPHOLYTES
}

The addition of N-chlorosulfonyl isocyanate (I) to unsaturated compounds has been studied extensively (1-3). There are however, no reports in the literature about the reaction of I with unsaturated polymers. Addition of I to $\mathrm{C}=\mathrm{C}$ bonds in polymers might ultimately lead to a suitable synthesis of polyampholytes. This reaction is analogous to the preparation of $\beta$-amino acids via addition of I to simple alkenes (1).

Various methods have been published on the preparation of synthetic polyampholytes (4-6), but the possibility of using I has not been explored. We wish to report some preliminary results of our investigations now.

\section{Experimental}

Poly-cis-1,4-isoprene (Cariflex/Shell BR 1220, cis content $>96 \%$ ) was dissolved in benzene $(0.10$ basal mole in $500 \mathrm{ml})$. This solution was added to a continuously stirred solution of 0.15 mole $I$ in $100 \mathrm{ml}$ benzene. The addition was carried out at room temperature in a nitrogen atmosphere. After about $15 \mathrm{~min}$ the solution became turbid and a precipitate was formed. This material was isolated and washed with diethylether (yield $17.2 \mathrm{~g}$ ).

The IR spectrum of the reaction product (II) showed a very strong absorption at $1810 \mathrm{~cm}^{-1}$, also found in $\beta$-lactam-N-sulfonylchlorides and is due to $\mathrm{C}=\mathrm{O}$ groups (2). A weak band at $1740 \mathrm{~cm}^{-1}$ can be assigned to a carbonyl absorption also present in spectra of $\beta$ - $\gamma$-unsaturated carbonamide- $\mathrm{N}$-sulfonylchlorides (7). Bands appearing at 1175 and $1405 \mathrm{~cm}^{-1}$ are an indication for the occurrence of $-\mathrm{SO}_{2} \mathrm{Cl}$ groups.

Given these data the reaction course can be depicted as shown in scheme A. The following elemental analysis of II was obtained:

$\begin{array}{llllll}\mathrm{C} & \mathrm{H} & \mathrm{O} & \mathrm{N} & \mathrm{S} & \mathrm{Cl} \\ 40.19 & 4.55 & 22.18 & 5.97 & 13.06 & 14.19\end{array}$

which can be written as $\left(\mathrm{C}_{6.00} \mathrm{H}_{8.15} \mathrm{O}_{2.48} \mathrm{~N}_{0.76} \mathrm{~S}_{0.73} \mathrm{Cl}_{0.72}\right)_{\mathrm{n}}$. A $100 \%$ addition to the isoprene units would give the formula $\left(\mathrm{C}_{6.00} \mathrm{H}_{8.00} \mathrm{O}_{3.00} \mathrm{~N}_{1.00}\right.$ $\left.\mathrm{S}_{1.00} \mathrm{Cl}_{1.00}\right)_{\mathrm{n}}$. Although the atomic ratio of $\mathrm{N}: \mathrm{S}: \mathrm{Cl}$ in the adduct is about $1: 1: 1$, the $0: \mathrm{N}$ ratio, however, is not $3: 1$, indicating not only addition of $\mathrm{I}$, but also a reaction path until now unknown to us.

$\beta$-Lactam-N-sulfonylchlorides can be hydrolyzed in basic medium, the

0

II

$-\mathrm{N}-\mathrm{C}-$ bond is broken and $\mathrm{N}$-substituted $\beta$-amino acid salts are formed (1). 
Scheme A<smiles>CCCCC</smiles>

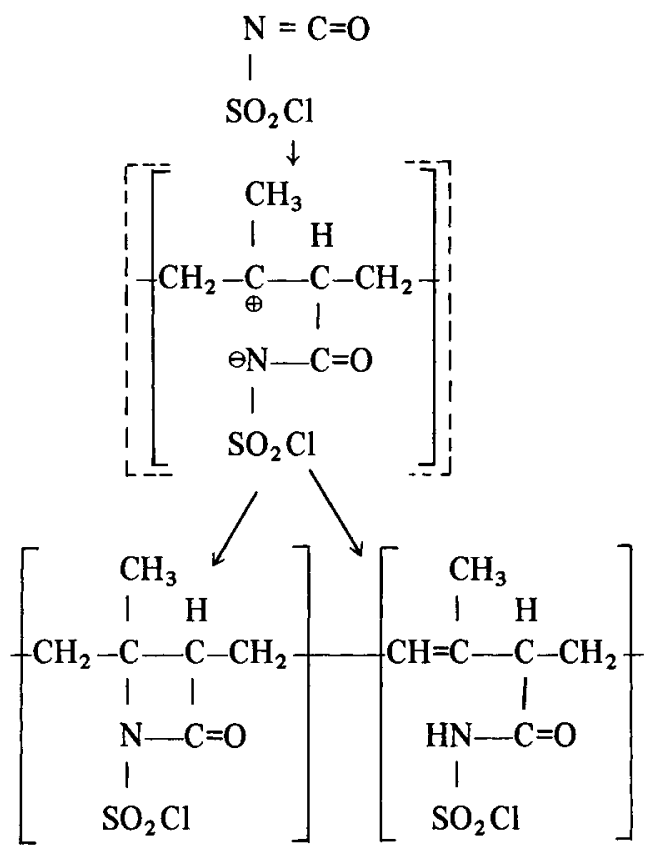

II

$10 \mathrm{~g}$ of II were therefore treated with $200 \mathrm{ml} 2 \mathrm{M} \mathrm{NaOH}$ and refluxed for 1 hr. The resulting solution was poured into $800 \mathrm{ml}$ methanol and subsequently the yellow-white powder $(4.3 \mathrm{~g})$ was isolated (III). The atomic ratio of the various elements in III was: $\mathrm{C}_{6.00} \mathrm{H}_{12.45} \mathrm{~N}_{0.74} \mathrm{~S}_{0.74} \mathrm{Na}_{1.52}$. It appeared to be difficult to reproduce the figures for the oxygen content. The figures varied from $36-45 \%$. We suppose III to contain the following structural units:

Scheme B<smiles>C/C(=C/C(C)(C)C(=O)O[Na])C(=O)O[Na]</smiles> 


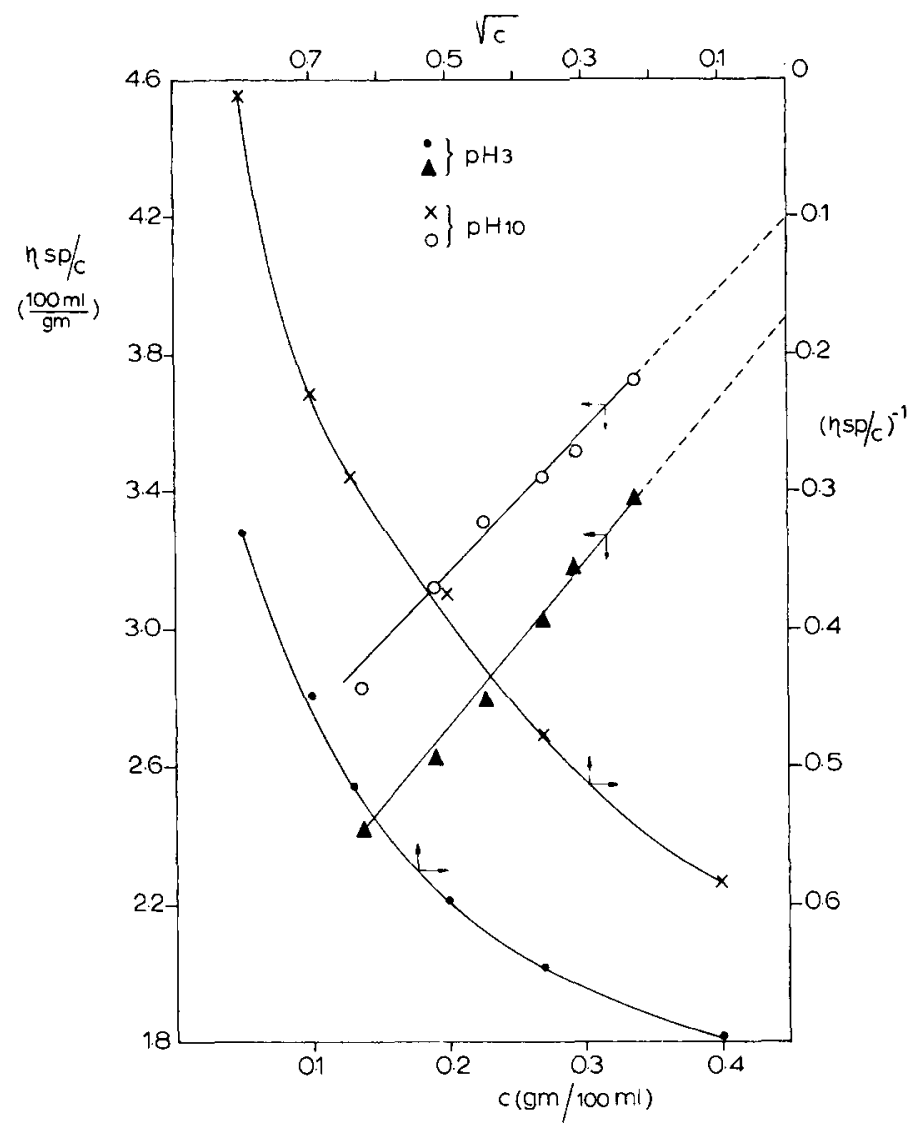

Fig. 1.

Viscometric Measurements of III in Water

The viscometric behavior of this product would give information about the polyelectrolyte character, thus providing support for structure II.

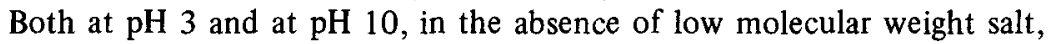
the reduced specific viscosity $\eta_{\mathrm{sp} / \mathrm{c}}$ increases with dilution, as can be seen from Figure 1.

At $\mathrm{pH} 3$ the carboxylic acid groups are unionized and the typical polyelectrolyte effect (8) results only from the mutual repulsion of the negatively charged aminosulfonate groups on the polymer chain. Raising the $\mathrm{pH}$ causes the carboxylic acid groups to dissociate; thus more negatively charged groups than at pH 3 may repel each other. The chain expands and there is an increase in the reduced specific viscosity at all concentrations. Plotting $\mathrm{c} / \eta_{\mathrm{sp}}$ versus $c^{1 / 2}$, using the Fuoss-Strauss equation (8): 


$$
\frac{\eta_{\mathrm{sp}}}{\mathrm{c}}=\frac{\mathrm{A}}{1+\mathrm{B} \sqrt{\mathrm{c}}}
$$

values of $\mathrm{A}(=[\eta]): 5.7$ and 10.0 at $\mathrm{pH} 3$ and $\mathrm{pH} 10$ are obtained, respectively. In the presence of $0.1 \mathrm{M} \mathrm{NaCl}$ at both $\mathrm{pH}$ 's a linear dependence of $\eta_{\text {sp }} / \mathrm{c}$ versus $\mathrm{c}$ is found, [ $\eta$ ] being 0.44 and 0.48 at $\mathrm{pH} 3$ and $\mathrm{pH} 10$, respectively.

Heating of III in an acid medium causes splitting of the N-S bond, leading to a polyampholyte. Results of these investigations and also of reactions of $\mathrm{I}$ with other unsaturated polymers will be published in a forthcoming paper.

The authors wish to thank Prof. Dr. A. Bantjes and Dr. J. W. A. van den Berg from this department for their helpful comments.

\section{References}

(1) R. Graf, Justus Liebigs Ann. Chem., 661, 111 (1963); Angew. Chem., 80, 179 (1968).

(2) P. Goebel and K. Clauss, Justus Liebigs Ann. Chem., 722, 122 (1969).

(3) E. J. Moriconi and Y. Shimakawa, J. Org. Chem., 37, 196 (1972).

(4) M. Vrancken and G. Smets, J. Polym. Sci., 14, 521 (1954).

(5) T. Alfrey and S. H. Pinner, J. Polym. Sci., 23, 533 (1957).

(6) C. H. H. Neufeld and C. S. Marvel, J. Polym. Sci., A-1, $\underline{5}, 537$ (1967).

(7) H. Bestian, H. Biener, K. Clauss, and H. Heyn, Justus Liebigs Ann. Chem, 718, 94 (1968).

(8) R. M. Fuoss and U. P. Strauss, J. Polym. Sci., $\underline{3}$, 246 (1948).

L. van der Does

J. Hofman

T. E. C. van Utteren

Polymer Chemistry Laboratory

Twente University of Technology

Enschede, The Netherlands

Received August 15, 1972

Revised January 30, 1973 